\title{
A Insustentabilidade do Turismo no Brasil e o Sucesso de Praia do Forte: uma análise exploratória com base na nova economia institucional
}

\author{
The Unsustainability of the Tourism Sector in Brazil and the Success of Praia \\ do Forte: an exploratory analysis base don the new institutional economics
}

\author{
Marcus Alban ${ }^{1}$
}

\section{Resumo}

Baseado no pressuposto de que o turismo é uma rota natural e fácil, a evolução do setor no país, desde os anos 90, tem se pautado por uma estratégia de forte expansão espacial da infraestrutura. Partindo-se de uma análise do baixo desempenho dessa estratégia, demonstra-se o equívoco desse pressuposto. A conclusão é de que o turismo não tem nada de natural ou fácil. Ao contrário é uma rota bastante complexa, que não pode se desenvolver sem boas estruturas de governança. Face a essa constatação, o artigo apresenta as linhas mestras da Nova Economia Institucional e, com base na mesma, analisa os complexos sistemas de governança das cadeias produtivas do setor. Posteriormente, de posse desse novo referencial, estuda-se a singular estrutura de governança do caso de Praia do Forte, na Bahia, um dos raros casos de desenvolvimento turístico sustentável no país.

Palavras chave: desenvolvimento turístico; sustentabilidade; estruturas de governança; Brasil; Praia do Forte.

\begin{abstract}
Based on the presupposed that the tourism is an easy and natural path, the evolution of this sector in the country, since the 90's, has adopted a strong strategy of spatial expansion of the infrastructure. Starting from an analysis of the low performance of this strategy, it shows the mistake of this presupposed. The conclusion is that the tourism is not easy or natural at all. On the contrary, it is a very complex path, which can not be developed without good governance structures. Facing this conclusion, the paper presents the main lines of the New Institutional Economics and, based on it, analyses the complex systems of the governance of the sector's productive chains. Subsequently, having this new referential, study the singular governance structure of the case of Praia do Forte, in Bahia, one of the unusual cases of sustainable tourism development in the country.
\end{abstract}

Keywords: tourism development; sustainability; governance structures; Brazil; Praia do Forte.

\footnotetext{
${ }^{1}$ Doutor em economia pela USP, professor do NPGA e coordenador do NCTUR da Escola de Administração da UFBA. E-mail: alban@uol.com.br
} 


\section{Introdução}

Com os desenvolvimentos sócio-econômicos empreendidos nos países centrais a partir do pós-guerra, o turismo, ao longo da segunda metade do século $\mathrm{XX}$, transformou-se num fenômeno de massas, criando um setor econômico dos mais importantes da atualidade. Tomado apenas em seus fluxos internacionais, o turismo, conforme os dados da OMT, expandiu-se ao longo das últimas duas décadas a taxas bastante elevadas, e já representa uma receita superior a 7,5 \% das exportações globais. De outro lado, com os desenvolvimentos tecnológicos empreendidos nas áreas de transportes e comunicações, este é um processo que se espraia por todo o mundo, criando várias oportunidades para os países em desenvolvimento (GEE e FAYOS-SOLÁ, 2003).

As oportunidades criadas pelo turismo não se resumem à magnitude do setor. Configurando literalmente um processo de importação de consumidores externos, o turismo potencializa a demanda interna das economias, possibilitando a "exportação" de bens e, sobretudo, serviços não comercializáveis (FERNANDES e COELHO, 2002). Assim, através do turismo é possível viabilizar a "exportação” de serviços como corridas de táxis e shows folclóricos. O turismo, nesse sentido, caracteriza-se por ser um setor que influencia fortemente a mão-deobra, o que amplia ainda mais a sua importância para os países em desenvolvimento (LAGE e MILONE, 1999).

Em que pesem essas dinâmicas e características, nem todos os países em desenvolvimento estão aproveitando adequadamente as oportunidades criadas pelo turismo. Esse, infelizmente, é o caso do Brasil, onde o setor, embora sempre tido como prioridade, não consegue avançar de modo satisfatório. De acordo com os últimos dados de 2004, o Brasil recebe apenas algo em torno de cinco milhões de turistas internacionais ao ano - bem menos do que países menores, como Tailândia e África do Sul, igualmente distantes dos grandes centros emissores ${ }^{2}$.

Para entender esse paradoxo do turismo no Brasil, no presente artigo, partindo-se de uma análise da estratégia em curso de expansão espacial do setor, demonstra-se que o desenvolvimento do turismo não tem nada de natural ou fácil, como em geral se supõe. Ao contrário, é uma rota bastante complexa, que não pode se desenvolver sem boas estruturas de

\footnotetext{
${ }^{2}$ Segundo dados da OMT, nesse mesmo ano de 2004 a África do Sul recebeu 6,81milhões de turistas internacionais e a Tailândia chegou 11,61 milhões (2005).
} 
governança. Face a essa constatação, o artigo apresenta as linhas mestras da Nova Economia Institucional, principal referencial teórico para o estudo das estruturas de governança, e, com base na mesma, analisa os complexos sistemas de governança das cadeias produtivas do setor, bem como de seus destinos. Posteriormente, de posse desse novo referencial, estuda-se a singular estrutura de governança do caso de Praia do Forte, na Bahia, um dos raros casos de desenvolvimento turístico sustentável no país, discutindo as possibilidades e os limites de generalização da mesma ${ }^{3}$.

\section{As Limitações da Estratégia de Infra-estrutura}

Em função do dinamismo internacional, sobretudo a partir dos anos 90, com a busca de uma estratégia de integração competitiva, o turismo passou a ser percebido no Brasil como um setor econômico ideal. Um setor de grande potencial para geração de emprego, renda e divisas, onde o país, por sua grande riqueza natural e cultural, seria naturalmente competitivo. Competitivo tanto para turistas, quanto para capitais estrangeiros que, desde que atendidos os requisitos mínimos de infra-estrutura, viriam naturalmente para o Brasil desfrutar e explorar as suas riquezas e belezas.

Importante observar que essa percepção do turismo como setor ideal não se restringia - nem se restringe - ao governo federal e aos estados e municípios. Com o boom do turismo no mundo nos anos 1990, também os organismos internacionais passaram a ver o setor como peça chave do processo de desenvolvimento ${ }^{4}$. Para eles, o turismo podendo viabilizar-se a partir de demandas externas, tinha também o mérito de possibilitar o desenvolvimento de países e regiões periféricas. Por outro lado, percebido como um setor potencialmente sustentável, acreditava-se que, com o turismo, garantir-se-ia um desenvolvimento com baixos impactos ambientais ${ }^{5}$.

\footnotetext{
${ }^{3}$ No presente trabalho adota-se o conceito de desenvolvimento sustentável em seu sentido mais amplo, incorporando, portanto, a viabilidade econômica de modo associado à sustentabilidade ambiental e social.

${ }^{4}$ Como observa Rodrigues: "experiências de outros países (...) apontam para o turismo e (...) o BID e o Bird não só aprovam, como o financiam” (2001, p.151).

${ }^{5}$ Dessa maneira, voltando a Rodrigues, "o turismo é apontado, sem restrições, como a grande alternativa para recuperar a economia, sendo alardeado como uma atividade econômica que, por sua própria natureza, é 'preservadora' do meio ambiente". Paralelamente, ainda segundo Rodrigues, o turismo seria percebido também como um preservador e indutor do desenvolvimento da cultura local (2001, p.156-157).
} 
Em outras palavras, pode se dizer que a partir dos anos 1990 o turismo passou a ser entendido por todos como uma rota natural e fácil para o rápido e equilibrado desenvolvimento sustentável do país. Com essa perspectiva, o governo, em suas várias esferas, passa a potencializar ativamente a expansão do setor, implantando e expandindo a infra-estrutura necessária nos segmentos de transportes, energia e apoio urbano. O Governo atua também na recuperação de vários sítios e centros históricos, bem como na implantação de inúmeros equipamentos culturais. A idéia era que, com a expansão da infra-estrutura e a recuperação do patrimônio histórico-cultural, os empreendedores e turistas naturalmente chegariam, desenvolvendo novas e mais amplas regiões do país. Segundo a própria Embratur:

a criação e melhoria da infra-estrutura da região induzirá crescentes investimentos privados em hotelaria, animação, gastronomia, artesanato e outros serviços de suporte do turismo, que repercutirão positivamente na arrecadação de impostos e tributos federais, estaduais e municipais com conseqüentes benefícios para a população local (1992, p.5).

Ainda que nem tudo tenha sido formalmente pensado, a implementação dessa estratégia de expansão da infra-estrutura foi em grande parte efetivada. Contando com o apoio dos organismos financeiros internacionais para a expansão da infra-estrutura pública, e de grandes investidores privados / institucionais para expansão da rede hoteleira e de resorts, os anos 1990, especialmente em sua segunda metade, foram pródigos em altos volumes de investimento no setor ${ }^{6}$.

Em que pese todo esse sucesso na implementação da estratégia, observa-se, entretanto, que os resultados alcançados, ao menos até o momento, deixam muito a desejar. Isso fica claro na evolução da chegada dos turistas internacionais, o grande mercado alvo da estratégia. Conforme a Tabela 1, as chegadas internacionais apresentam um grande incremento em 1998. Esse dado, no entanto, não reflete o sucesso da estratégia. Trata-se apenas de uma mudança de metodologia para a contagem dos turistas internacionais que ingressaram no país por via terrestre. Assim, se tomamos o período 1998-2000, onde se manteve a mesma metodologia, observa-se um crescimento médio em torno de 5\% ao ano. Esse número, embora elevado para os atuais padrões de crescimento do PIB brasileiro, é inferior à média de crescimento do turismo no mundo nesse mesmo período. Em 2001 e 2002, por outro lado, as chegadas internacionais sofrem um grave revés, minorado apenas parcialmente em 2003 e 2004.

\footnotetext{
${ }^{6}$ A expansão da infra-estrutura pública se deu sobretudo no Nordeste através do chamado PRODETUR. Um programa que em sua primeira etapa, 1993-2001, significou um investimento de US\$ 800 milhões na região, financiado em 50\% pelo BID (www.bancodonordeste.gov.br/prodetur). Para a análise do papel exercido pelos investidores institucionais, os fundos de pensão, nesse período, ver Proserpio (2003, p. 61-65).
} 
Tabela 1 - Brasil - Número de Turistas Internacionais por Região de Procedência

\begin{tabular}{l|c|c|c|c|c|c|c|c|c}
\hline $\begin{array}{r}\text { Regiões/ Turistas } \\
\text { em mil }\end{array}$ & 1996 & 1997 & 1998 & 1999 & 2000 & 2001 & 2002 & 2003 & 2004 \\
\hline - América do Norte & 406 & 460 & 608 & 648 & 744 & 693 & 753 & 787 & 839 \\
\hline - América do Sul & 1406 & 1520 & 2810 & 2962 & 3036 & 2418 & 1459 & 1580 & 1829 \\
\hline - Europa & 671 & 702 & 1145 & 1228 & 1306 & 1431 & 1376 & 1522 & 1834 \\
\hline - Outros & 183 & 168 & 255 & 269 & 227 & 231 & 195 & 244 & 292 \\
\hline Total & 2666 & 2850 & 4818 & 5107 & 5313 & 4773 & 3783 & 4133 & 4794 \\
\hline
\end{tabular}

Fonte: Anuário Estatístico da Embratur (vários anos).

Descendo a análise para o nível micro-regional, observa-se paralelamente que os investimentos em infra-estrutura não vêm engendrando as esperadas dinâmicas sustentáveis de crescimento. De fato, especialmente nos complexos turísticos de sol e praia das costas nordestinas, o que se constata, na grande maioria dos casos, é justamente o contrário. A infraestrutura chega, viabiliza o boom turístico, mas não o sustenta. Assim, logo em seguida vem a saturação e a degradação social e ambiental dos complexos (ver Figura 1) ${ }^{7}$.

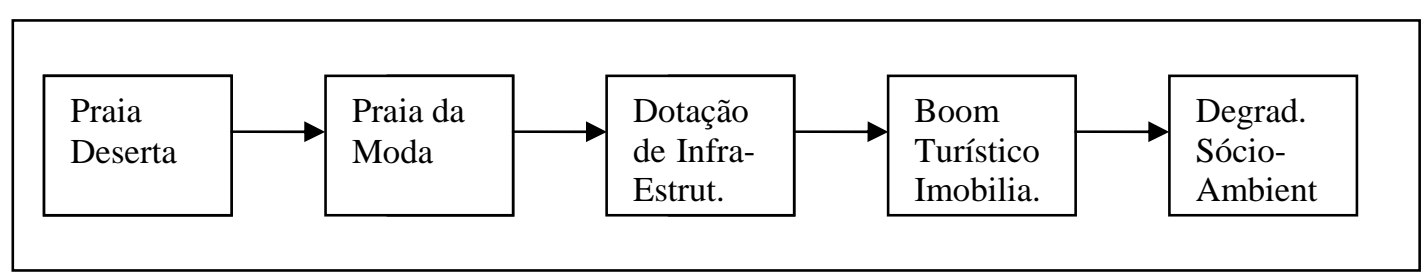

Figura 1 - Dinâmica Perversa do Turismo nas Costas Nordestinas

Nem todos os complexos de sol e praia nordestinos têm apresentado a dinâmica perversa acima descrita. Sem dúvida existem exceções, como a do complexo de Praia do Forte na Bahia, onde o turismo vem se desenvolvendo de maneira sustentável já há bastante tempo. Essas exceções, contudo, não passam de exceções. Além de pouco expressivas na oferta regional, não se mostraram capazes de conformar dinâmicas padrões para os demais destinos. Assim, com a expansão espacial da infra-estrutura, o que viceja mesmo é a dinâmica perversa.

\footnotetext{
${ }^{7}$ Tomando-se o caso da Bahia como exemplo, a maior economia turística do Nordeste, essa dinâmica perversa reflete, com razoável exatidão, os processos vividos nas regiões de Itaparica, Morro de São Paulo, IlhéusOlivença e Porto Seguro. Processos muito parecidos, por outro lado, parecem estar em curso nos complexos turísticos mais recentes, das regiões de Itacaré, Baía de Camamú e de boa parte do Litoral Norte (ALBAN, 2004). De fato, a única exceção efetiva, até o momento, é o complexo de Praia do Forte, também no Litoral Norte, analisado mais adiante.
} 


\section{A Necessidade de Boas Estruturas de Governança}

Naturalmente é ainda muito cedo para se chegar a uma conclusão definitiva quanto ao equívoco dessa estratégia de expansão espacial. Não resta dúvida, entretanto, que o desempenho já alcançado não é nada positivo ${ }^{8}$. Mas, por que isso aconteceu e continua acontecendo? Por que as dinâmicas virtuosas, da Praia do Forte, não se tornam dominantes? Por que com a expansão da infra-estrutura pública e a implantação e recuperação de tantos hotéis, resorts, pousadas e centros históricos, o turismo brasileiro não deu, nem dá, o tão esperado salto?

Essas são questões fundamentais para uma real compreensão do turismo brasileiro. Para respondê-las, entretanto, é preciso que abandonemos a perspectiva estritamente física do setor. De fato, o que as evidências indicam é que o turismo, ao contrário do que supõe a estratégia de expansão espacial, não é uma atividade simples, nem natural. Ao contrário, é uma atividade extremamente complexa, cujo desenvolvimento, além da infra-estrutura física, exige sofisticadas estruturas de governança.

Frente a esse contexto, nos subitens a seguir apresentamos as linhas mestras da Nova Economia Institucional, principal referencial teórico para o estudo das estruturas de governança, e com base na mesma analisamos os complexos sistemas de governança das cadeias produtivas de turismo. Posteriormente, de posse desse novo referencial, analisamos no item final a singular estrutura de governança do caso de Praia do Forte, discutindo as possibilidades e os limites de generalização da mesma.

\subsection{A Nova Economia Institucional}

Com a Grande Depressão os anos 30 explicitarão a importante dicotomia entre o saber teórico e a economia real. De fato, a economia não tendia para o pleno emprego, como se previa, e isso possibilitava e exigia novas teorias. É nesse contexto que surge a Teoria Geral de Keynes, que dará origem a macroeconomia, e também várias outras abordagens microeconômicas, como a formulada por Ronald Coase em The Nature of the Firm de 1937 (1988, cap.2). Percebendo a firma como um sistema de coordenação de atividades alternativo ao mercado, Coase dará as bases para uma nova compreensão da estrutura econômica.

\footnotetext{
${ }^{8}$ Importante observar que, nessa análise, estamos considerando apenas os impactos diretos do turismo. Ou seja, os impactos de fluxo e renda gerada. Assim, não estamos considerando a questão dos multiplicadores onde existem também sérios problemas. Sobre esse ponto, e também considerando o caso baiano, ver Silva (2004).
} 
Constatando a existência das duas formas de coordenação, a firma e o mercado, Coase tenta entender a coexistência das mesmas. Ou seja, por que existem firmas, por que tudo não é transacionado e coordenado via mercado e, já que existem firmas, "por que toda a produção não é realizada numa grande firma?” Coase irá concluir que, além dos custos de produção, existem também os custos de transação para a coordenação do sistema. Em sua análise, esses seriam os custos de coleta de preços, negociação e estabelecimento de contratos. Assim, como a transação via mercado não se dá sem custos, a firma irá se desenvolver sempre que seus custos de transação internos forem inferiores aos custos do mercado, e vice versa.

Em que pese relevância dos achados de Coase, sua incorporação à teoria econômica não foi imediata. Ao contrário demorou um longo tempo. Ocorre que os custos de transação, conforme apresentados, não eram de fácil mensuração - como separar os custos de transação dos custos de produção? Coase não aprofundara questões como essas, e assim, era impossível verificar se as firmas eram verdadeiramente estruturas minimizadoras de custos de transação. Os achados de Coase, nesse sentido, exigiram a contribuição de outros pesquisadores até que se conformasse uma nova abordagem de análise da estrutura econômica - a abordagem da Nova Economia Institucional, a NEI.

Em sua sistematização contemporânea, conformada em grande parte através dos trabalhos de Oliver Williamson (1985, 1991 e 1996) e Douglas North (1981, 1990 e 1994), a Nova Economia Institucional estrutura-se a partir de dois pressupostos comportamentais básicos: o da Racionalidade Limitada ( $1^{\circ}$ pressuposto) e o do Oportunismo $\left(2^{\circ} \text { pressuposto }\right)^{9}$. O primeiro pressuposto argumenta que os agentes econômicos, embora almejando o comportamento racional, apresentam naturais limites cognitivos no processo de receber, estocar e processar informações. A racionalidade, desta maneira, não é plena como pressupõe a ortodoxia econômica, mas sim, limitada.

Se a racionalidade é limitada, isso significa que os contratos, para dar conta de todas as contingências envolvidas em transações mais complexas, são naturalmente incompletos. Desse modo, os custos de transação não podem ser reduzidos aos de mera captação de informação e elaboração de contratos, sejam estes formais ou informais. Ou seja, a não previsão de todas as contingências será também um custo de transação, e isso se agrava em função do segundo pressuposto comportamental, o do oportunismo dos agentes. 
O pressuposto do oportunismo postula que os agentes atuam buscando seu auto interesse. Desse modo, mesmo que os agentes não sejam mentirosos e trapaceiros (casos extremos de auto-interesse), a incompletude dos contratos pode implicar em dificuldades de renegociação e, conseqüentemente, perdas para ao menos um dos agentes na ocorrência de eventos e contingências não previstas. Naturalmente, todos esses problemas e riscos são também custos de transação.

Como se observa, com os pressupostos comportamentais da racionalidade limitada e do oportunismo, a NEI configura a existência de custos de transação bem mais amplos dos que os pensados por Coase. Assim, numa definição mais contemporânea formulada por Williamson, os custos de transação são tidos como:

os custos ex-ante de preparar, negociar e salvaguardar um acordo / contrato, bem como os custos ex-post dos ajustamentos e adaptações que resultam quando a execução de um contrato é afetada por falhas, erros, omissões e alterações inesperadas (1996).

Definindo e explicitando o custo de transação como o custo de conduzir o sistema econômico, a NEI procura, em uma de suas principais linhas de pesquisa, estudar o desenvolvimento das estruturas de governança criadas para reduzir esses custos. Nesse sentido, segundo essa linha, também denominada de Economia dos Custos de Transação, a estrutura de governança será concebida como "o meio pelo qual se faz cumprir a ordem em uma relação onde o conflito potencial ameaça desfazer ou perturbar as oportunidades de realização de ganhos mútuos” (WILLIAMSON, 1975).

As estruturas de governança não agem no vazio. Ao contrário, atuam dentro de um ambiente institucional, onde são definidos os parâmetros e as possibilidades de atuação das várias organizações / estruturas de governança. O estudo do Ambiente Institucional constitui, assim, outra importante linha de pesquisa da NEI. Segundo North, principal pesquisador dessa linha, o ambiente institucional será constituído pelas instituições, formais e informais, conformando “as regras do jogo” (1990). Como se percebe, as duas linhas de pesquisa trabalham em níveis complementares do processo de coordenação sócio-econômica.

Voltando à análise das estruturas de governança, a NEI, seguindo as formulações originais de Coase, irá considerar a existência de dois tipos básicos: o mercado, onde a coordenação se

\footnotetext{
${ }^{9}$ Na análise síntese desenvolvida a seguir, salvo referência em contrário, segue-se sempre os trabalhos acima citados. Para uma análise mais ampla da NEI, abordando a contribuição de vários outros autores, ver Azevedo (1997) e Zylbersztajn (1995).
} 
estabelece pela sinalização da variação dos preços, e a firma, onde a coordenação se dá pela autoridade de fiat, através da hierarquia administrativa ${ }^{10}$. Mesclando esses dois tipos básicos, existem as estruturas híbridas que se estabelecem através de contratos, mais ou menos amplos e ou restritivos.

A existência de vários tipos de estruturas de governança decorre do fato de haverem também vários tipos de transação. Sucede que, se as estruturas de governança buscam a redução dos custos de transação (a rigor, de transação e produção), e as transações e seus custos diferem entre si, nada mais lógico do que a existência de estruturas distintas. Nesse sentido, entender como se diferenciam as transações, e quais as estruturas mais adequadas a cada tipo, constitui uma das preocupações centrais da NEI.

Em linhas gerais, as transações podem ser analisadas a partir de três dimensões básicas: especificidade de ativos, freqüência e incerteza. A especificidade de ativos, como o próprio nome indica, está associada à utilização de ativos voltados para fins específicos, nos quais se detém elevada produtividade. Trata-se assim, da utilização de ativos de alta produtividade e baixa flexibilidade. Essa dupla característica faz dos ativos específicos bens simultaneamente valiosos e arriscados. De fato, se o ativo é específico, ele só pode ser voltado para fins distintos da sua especificidade às custas de grandes perdas de valor. Assim, quanto maior a especificidade do ativo, maior será, tanto o seu valor potencial, quanto o risco / custo de transação envolvido na sua utilização ${ }^{11}$.

A freqüência, que constitui a segunda dimensão básica, impacta na transação através de duas maneiras. Em primeiro lugar, ela possibilita a diluição dos custos relativos à busca de informações e elaboração de contratos. Ou seja, quanto mais freqüente a transação, menor será o custo unitário dos mecanismos criados para a sua efetivação. O contrário, naturalmente, é também verdadeiro. Em segundo lugar, a freqüência viabiliza também a redução absoluta dos custos de transação. Isso ocorre tanto em razão da possibilidade de adoção de mecanismos de retaliação, o que inibe possíveis comportamentos oportunísticos, quanto da possibilidade do desenvolvimento de reputação / valorização de marcas.

\footnotetext{
${ }^{10}$ O termo fiat equivale a "seja feito" em latim.

11 Conforme observa Azevedo, analisando a questão Williamson distingue a existência de seis tipos de especificidade de ativos: “a) especificidade locacional - a localização próxima de firmas de uma mesma cadeia produtiva (...); b) especificidade de ativos fixos; c) especificidades de ativos humanos (...); d) ativos dedicados relativos a um montante de investimento cujo o retorno depende da transação com um agente particular (...); e) especificidade de marca (...) particularmente relevante no mundo das franquias; e f) especificidade temporal, em que o valor da transação depende sobretudo do tempo em que ela se processa (1997, p.86-87).
} 
A terceira dimensão por fim, consiste na incerteza. A incerteza, que pode ser percebida como o desconhecimento das possibilidades dos eventos futuros, por uma ou ambas as partes, afeta a transação aumentando diretamente o seu custo ${ }^{12}$. De fato, dados os pressupostos de oportunismo e racionalidade limitada, quanto maior a incerteza, maiores os riscos e, portanto, os custos envolvidos na transação.

Naturalmente, as três dimensões básicas não existem isoladamente. Ao contrário existem e atuam interativamente nas transações, exigindo a constituição de distintas estruturas de governança. Em linhas gerais, dado certo ambiente institucional, se tanto a especificidade de ativos quanto a freqüência e a incerteza são baixas, tende-se para uma estrutura de mercado. Já no caso contrário, quando a especificidade de ativos e a incerteza são muito elevadas, e a freqüência não existe ou, dada a incerteza, não pode ser garantida, tende-se para hierarquias administrativas internas. Em casos intermediários a solução caminha para estruturas híbridas com base em contratos.

\subsection{A questão dos bens públicos}

Como visto, a NEI desenvolveu um amplo aparato teórico para lidar com a as estruturas de governança voltadas para a organização da produção de bens privados. As estruturas de governança, no entanto, não existem apenas na produção de bens privados. De fato, como extensão do ambiente institucional, elas permeiam toda a economia, tendo um papel também decisivo na organização da produção e distribuição dos chamados bens públicos.

A definição dos bens como privados ou não privados / públicos está associada a dois atributos básicos: o potencial de exclusão e a rivalidade de consumo. Por potencial de exclusão entende-se a capacidade do produtor / vendedor de excluir do consumo todos aqueles que não atendam as condições exigidas pelos mesmos. Importante acrescentar que o potencial de exclusão pode ser elevado, baixo, ou mesmo inexistente, por questões tanto técnicas quanto econômicas. Assim, muitas vezes existe a possibilidade técnica de exclusão, mas não é economicamente viável efetivá-la.

Por rivalidade de consumo, que também pode ser alta ou baixa, entende-se a impossibilidade de consumo concomitante por dois ou mais demandantes. Se a rivalidade é alta o consumo por um demandante esgota e ou degrada totalmente o bem. Assim, se a rivalidade é alta, o

\footnotetext{
${ }^{12}$ Se a incerteza é unilateral, tem-se o clássico problema da assimetria de informações.
} 
consumo de um bem por um demandante inviabiliza completamente o consumo do mesmo pelos demais. Se, ao contrário, a rivalidade é baixa, um mesmo bem, ao menos dentro de determinados limites, pode ser consumido concomitantemente por vários demandantes sem nenhum problema.

Adotando como em Ostrom e Ostrom (1977) a conjunção simultânea desses dois atributos, podemos definir então os vários tipos de bens. Como se observa no Figura 2, no primeiro quadrante estão os bens que apresentam alto potencial de exclusão, simultaneamente a uma alta rivalidade ao consumo. Por essas características, esses são os bens privados que, salvo problemas de externalidades e de fortes economias de escala, tendem a ser supridos e organizados diretamente pelo mercado. Bens não duráveis e duráveis, bem como serviços pessoais, são bons exemplos desse tipo de bens.

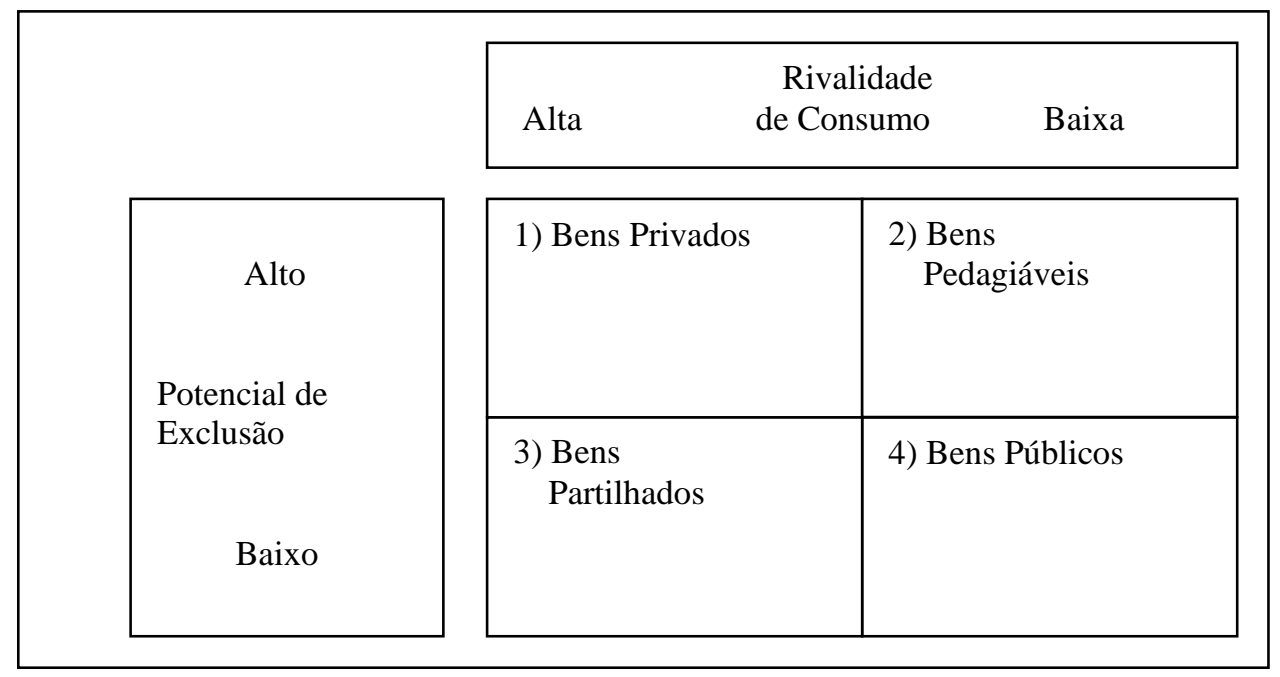

Figura 2 - Tipologia de Bens

Fonte: adaptado de Ostrom e Ostrom (1977).

Naturalmente, nos demais quadrantes estão os bens não privados que deixam de possuir ao menos uma das características do primeiro quadrante. Assim, no quadrante 2 estão os bens pedagiáveis, que, embora apresentando um alto potencial de exclusão, possibilitam, dentro de determinados limites, o consumo conjunto pela baixa rivalidade. Estes bens, dado o potencial de exclusão, podem ser ofertados e explorados privadamente. Contudo, como tendem a apresentar elevadas economias de escala, tendem a exigir a participação e ou regulação de agentes / estruturas não privadas para a garantia do bom funcionamento e a contenção de 
abusos de poder econômico. Bens como teatros, TVs a cabo e telefonia fixa são bons exemplos desse quadrante.

No quadrante 3 a dinâmica se inverte. Nele, a rivalidade de consumo é alta, mas o potencial de exclusão é baixo. Se isso acontece têm-se os bens partilhados, quase sempre associados a recursos naturais (água, petróleo, peixes, animais silvestres, etc.), que não podem ser explorados diretamente pelo mercado. Sucede que, como o potencial de exclusão é baixo, e os agentes estão sujeitos a comportamentos oportunísticos, não existem incentivos naturais à produção ou mesmo à simples manutenção desse tipo de bens / recursos. Assim, para evitar a sub produção ou a super exploração, torna-se necessária a adoção de estruturas supra-mercado para provimento e ou regulação das atividades de produção / distribuição.

No quadrante 4, por fim, têm-se os bens não privados no seu extremo. Ou seja, os Bens Públicos puros onde tanto o potencial de exclusão, quanto o atributo de rivalidade são muito baixos. Com essas características, os bens públicos, quase sempre envolvendo serviços universais (segurança, preservação ambiental e telecomunicações), também não podem ser produzidos / explorados diretamente pelo setor privado. Da mesma forma que os bens do quadrante 3, como o potencial de exclusão é baixo, não existem incentivos naturais à produção / manutenção desse tipo de bens. Por outro lado, como a rivalidade também é baixa, as economias de escala tendem a ser relevantes, sugerindo estruturas monopolísticas. Neste sentido, para evitar a sub-produção ou a super-exploração, também no quadrante 4 torna-se necessária a adoção de estruturas supra-mercado para provimento e ou regulação das atividades de produção / distribuição.

\subsection{Analisando a cadeia produtiva do turismo}

Como se observa na Figura 3, a cadeia produtiva do turismo apresenta uma marcante singularidade vis a vis as demais cadeias produtivas. De fato, enquanto nos demais setores parte-se da fonte de matérias primas, e caminha-se mediante transformações sucessivas em direção ao mercado, no turismo é o mercado que, transformado em turista, vai até a "matéria prima” da região ou cidade turística. Esta singularidade, que faz com que o consumidor passeie por quase toda a cadeia produtiva, implica, naturalmente, em estruturas de governança bem mais complexas do que as existentes nos demais setores.

A singularidade da cadeia produtiva do turismo é uma velha conhecida dos estudiosos da área. Assim, são inúmeros os trabalhos que apresentam o setor como um sistema produtivo 
complexo, tendo como eixo ou centro o próprio turista (BENI, 1998; GARRIDO, 2002 e PETROCCHI, 2001). Essa literatura, contudo, embora relevante, não desenvolve de maneira adequada a análise teórica e estratégica das respectivas estruturas de governança. O fato é que falta à mesma uma abordagem mais apropriada ao estudo da transação. Nesse contexto, a Nova Economia Institucional, a NEI, constitui um paradigma auxiliar bastante interessante.

Tomando-se a NEI como base, pode-se perceber que a cadeia produtiva do turismo é constituída por uma série de ativos de extrema especificidade. Isso é verdade, sobretudo, no caso dos sistemas de hospedagem. Um hotel de uma dada região praticamente não tem outra finalidade se não hospedar turistas naquela região. Nesse sentido, existe uma forte especificidade locacional, potencializada pelo aspecto temporal - as vagas de um hotel não podem ser estocadas, o que implica numa elevada perecibilidade do produto.

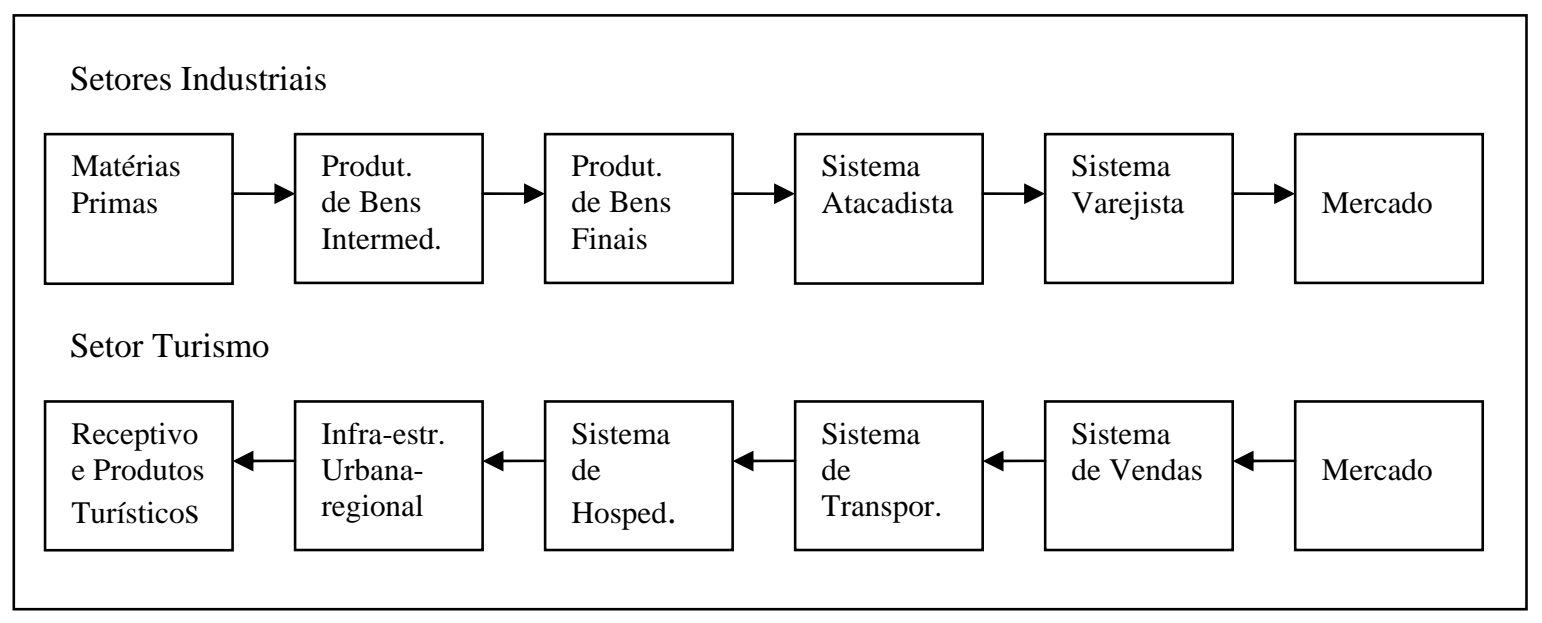

Figura 3 - Fluxo Básico nas Cadeias Produtivas

Paralelamente, deve-se observar que a freqüência das transações, especialmente nas pequenas localidades voltadas exclusivamente para o turismo de lazer, é em geral muito baixa. De fato, muitas vezes o turista só vai a uma dada localidade uma vez na vida. Se isso acontece, além da assimetria de informações, não existe a possibilidade de desenvolvimento natural de reputação, nem de adoção de mecanismos de retaliação. Dessa maneira, não existem estímulos para o estabelecimento de uma concorrência virtuosa via investimentos em qualidade. Ao contrário, o que se estabelece, não só entre os hotéis, é uma concorrência 
predatória que amplia a incerteza para o turista e degrada, via seleção adversa, todo o destino ${ }^{13}$.

Como se constata, os custos de transação são muito elevados no turismo e, se não controlados, inviabilizam qualquer destino. Assim, para que o setor avance, torna-se necessário o desenvolvimento de boas estruturas de governança. Em linhas gerais, são três os tipos básicos de instrumentos / arranjos institucionais utilizados na formulação das estruturas setoriais: sinalização, integração horizontal e integração vertical.

Na sinalização o objetivo é claramente reduzir a assimetria de informações e, portanto, a incerteza por parte do turista. Em linhas gerais, a sinalização se processa através de alguma instituição / mecanismo de certificação e classificação dos equipamentos, fornecendo ao turista as informações necessárias à correta avaliação do bem ou serviço desejado ${ }^{14}$. Desse modo, com a sinalização, desde que idônea, premia-se a qualidade e inviabilizam-se os comportamentos oportunísticos que engendram a concorrência predatória e a seleção adversa.

Na integração horizontal, que se dá através da criação de cadeias / redes de hotéis, o objetivo é desenvolver a reputação, internalizada nas respectivas marcas. Isso é possível porque, com a integração horizontal, viabiliza-se a ampliação da freqüência na medida em que o turista pode ir a várias localidades utilizando sempre a mesma cadeia de hotéis. Assim, com a integração horizontal, reduz-se também a incerteza dos turistas e, por conseqüência, os custos de transação de todo o sistema. Com custos menores, por outro lado, viabiliza-se, via descontos ou bônus, toda uma série de políticas de fidelização.

Na integração vertical por fim, tem-se, em maior ou menor grau, a articulação do hotel com a empresa transportadora e as agências de viagem e receptivo. Essa articulação, quase sempre efetivada através da coordenação de uma grande operadora, também possibilita a redução do custo de transação de todo o sistema. De fato, além das naturais economias de escala e escopo geradas com a integração vertical, não só o turista pode fazer várias viagens com a mesma agência, como a agência pode vender vários pacotes da mesma operadora. A operadora, por sua vez, pode contratar sucessivos serviços com o mesmo hotel, companhia área e agências de receptivo. Se isso acontece, com a integração vertical viabiliza-se a expansão da freqüência,

\footnotetext{
${ }^{13}$ Vale observar que o conceito de concorrência predatória não é o de prática de preço predatório, mas o de estratégias de baixa qualidade crescente, decorrente da incapacidade dos ofertantes de apresentar a qualidade dos produtos. Assim, via seleção adversa, eliminam-se os ofertantes de maior qualidade (AKERLOFF, 1970).

${ }^{14}$ Para uma boa visão dos vários tipos de sinalização adotados ver, GEE e FAYOS-SOLÁ (2003, p.60).
} 
possibilitando o desenvolvimento de reputação e redução da incerteza ao longo de toda a cadeia produtiva.

Naturalmente, esses três instrumentos (sinalização, integração horizontal e integração vertical) não são estanques. De maneira geral, são combinados em proporções diversas na conformação das estruturas de governança de cada cadeia / destino turístico. Cada instrumento, por sua vez, apresenta também conformações diversas. Os mecanismos de sinalização, por exemplo, podem ser implementados por órgãos públicos, não governamentais, ou mesmo empresas privadas independentes. Já as integrações verticais e horizontais, que substituem e ou complementam os mercados, podem se dar dentro de uma mesma hierarquia administrativa ou através de estruturas híbridas diversas via contratos.

Reduzindo os custos de transação ao longo de toda a cadeia, as estruturas de governança viabilizam a adoção de estratégias de qualidade e produtividade crescentes através de investimentos em ativos de especificidades também crescentes. Isso, contudo, não resolve todos os problemas do setor. Como visto, no turismo o consumidor é transportado até a origem da matéria prima. Ou seja, transportado até o destino turístico para viver as suas atrações. Nesse sentido, o turista não consome apenas as atrações, mas também a própria região de destino com todas as suas qualidades e mazelas.

Esse aspecto é de extrema importância nos países em desenvolvimento onde as mazelas sociais são ainda muito grandes. O problema, entretanto, não se resume apenas às mazelas em si. Ocorre que, como as atrações turísticas são quase sempre bens não privados / públicos, a exploração das mesmas é algo bastante complexo. De fato, sejam as atrações turísticas bens naturais, como praias, cachoeiras, canyons e florestas, ou bens culturais, como parques, centros históricos e festas populares, tem-se quase sempre a característica de baixa rivalidade ao consumo, juntamente com o baixo potencial de exclusão, o que não viabiliza, e ou permite, a simples exploração privada das mesmas.

Como visto anteriormente, o problema da governança dos bens não privados / públicos não é particular dos países em desenvolvimento. Neles, contudo, em função das mazelas sociais, ele sem dúvida se agrava. Isso é verdade, tanto pelos problemas de renda que dificultam o provimento dos bens públicos construídos diretamente pelo Estado, quanto pela maior pressão para exploração dos bens públicos-naturais. Importante observar, que essa maior pressão não se dá apenas por parte da população de baixa renda, mas também por grande parte do 
empresariado que, naturalmente, percebe no turismo uma das poucas opções de demanda existentes.

Nesse contexto, o desenvolvimento de destinos turísticos exige não apenas estruturas de governança das cadeias produtivas, mas também estruturas supra-mercado para a produção e manutenção das respectivas atrações turísticas. De uma maneira geral, se o Estado não tem recursos para prover e manter diretamente os bens públicos que constituem as atrações, é preciso criar arranjos institucionais que viabilizem a produção e exploração privada dos mesmos. Os instrumentos para isso envolvem processos como: criação de resorts destinos, ordenamento da exploração privada, planejamento e ordenamento do uso do solo, regulação ambiental, etc.

Da mesma forma que nas estruturas de governança das cadeias produtivas, o uso desses instrumentos e processos não se dá de maneira estanque. Ao contrário, são combinados de maneiras diversas de modo a atender as especificidades de cada caso. De outro lado, deve-se notar que existe também um processo interativo entre as duas estruturas, na medida em que, quanto melhor for a estrutura do destino, menor será a incerteza a ser enfrentada pela estrutura da cadeia produtiva e vice-versa. O conhecimento em toda essa área, entretanto, especialmente nos países em desenvolvimento, é ainda muito incipiente.

\section{Praia do Forte: a exceção não generalizável}

Tomando-se por base o referencial da NEI fica relativamente fácil compreender a insustentabilidade da estratégia turística seguida nos últimos anos. De fato, se belas praias desertas são tornadas acessíveis por modernas infra-estruturas de transportes, o mais natural é que se gere imediatamente a pressão por um boom de empreendimentos turísticos e imobiliários. Como isso, via de regra, ocorre em pequenos municípios, de baixa ou nenhuma capacidade administrativa, o boom se realiza sem nenhum planejamento e o bem público, que é a praia, rapidamente se satura e se degrada. Isso, entretanto, não foi o que aconteceu em Praia do Forte ${ }^{15}$.

\footnotetext{
${ }^{15} \mathrm{Na}$ análise desenvolvida a seguir, além do conhecimento obtido em entrevistas informais com empresários e moradores da região de Praia do Forte, segue-se de perto os dados apresentados nos trabalhos de Cardoso (2005) e Gomes (1997).
} 
Localizada no município de Mata do São João no Litoral Norte da Bahia (70 km acima de Salvador), o complexo de Praia do Forte é um exemplo de desenvolvimento turístico sustentável. Iniciado nos anos 80, o complexo vem crescendo desde então de maneira razoavelmente equilibrada. Isso não se deve a dificuldades de acesso, nem a nenhuma particularidade da prefeitura local. Já nos ano 80 Praia do Forte era conectada a Salvador por uma boa rodovia e a prefeitura de Mata de São João, ao menos até recentemente, era tão precária quanto a de qualquer outro pequeno município do interior baiano.

As razões para o excepcional sucesso de Praia do Forte decorrem fundamentalmente do fato dela ter tido um único dono - o paulista e neto de alemães, Klaus Peters, que ao final dos nos anos 70 comprou por US\$ 500 mil a antiga Fazenda de Praia do Forte. São 30 mil hectares de área costeira, localizados ao longo de $14 \mathrm{~km}$ de belas praias e entre os rios Pojuca e Imbassaí - tudo isso junto com as ruínas do antigo castelo (o forte) de Garcia D’Ávila e uma típica vila de pescadores. Vislumbrando o enorme potencial turístico da região, esse empresário, já nos anos 80, não só construiu um resort a beira mar, como criou a Fundação Garcia D’Ávila para planejar e gerenciar o desenvolvimento da área.

Administrado até 1989 por duas cadeias alemãs, e posteriormente pelo próprio Klaus Peters, o Praia do Forte EcoResort, como é chamado hoje, mostrou-se um grande empreendimento. Seu sucesso, entretanto, não decorre apenas do bom acesso às redes internacionais e das boas práticas gerenciais sempre adotadas. De fato, o grande sucesso desse EcoResort, que se expressa em tarifas e taxas de ocupação bem superiores às da média do setor, se deve sobretudo ao que aconteceu no seu entorno. Deve-se, portanto, à ação da Fundação Garcia D’Ávila, a FGD, em toda a Praia do Forte.

Como principal planejadora e gestora do desenvolvimento da área, a FGD desenvolveu e implementou um verdadeiro projeto de uso e ocupação ordenada do solo. Assim, não só os terrenos foram sendo vendidos de modo muito gradativo, como o uso dos mesmos foi regulado por restrições bastante rígidas. Essas restrições, especificadas nos contratos de compra e venda, definiam, e definem, desde a possibilidade, ou não, de uso comercial do terreno, até limitações arquitetônicas e paisagísticas, como o estabelecimento de uma altura máxima de 10 metros - que é o tamanho de um coqueiro adulto - para todas as construções.

As ações da FGD não se resumiram, entretanto, ao planejamento urbanístico arquitetônico da área. De fato, como se observa no Quadro 1, ela atuou, e permanece atuando, de maneira 
muito decisiva no processo de preservação e desenvolvimento do patrimônio ambiental e social de toda a região. Dessa maneira, com a coordenação da FGD, tornou-se possível engendrar um desenvolvimento turístico extremamente virtuoso e sustentável.

Quadro 1 - Políticas e Ações da Fundação Garcia D’Ávila

\begin{tabular}{|c|c|}
\hline Políticas & Desdobramentos e Ações \\
\hline $\begin{array}{l}\text { Atração de ONGs, } \\
\text { criação de reservas e } \\
\text { outras ações ambientais }\end{array}$ & 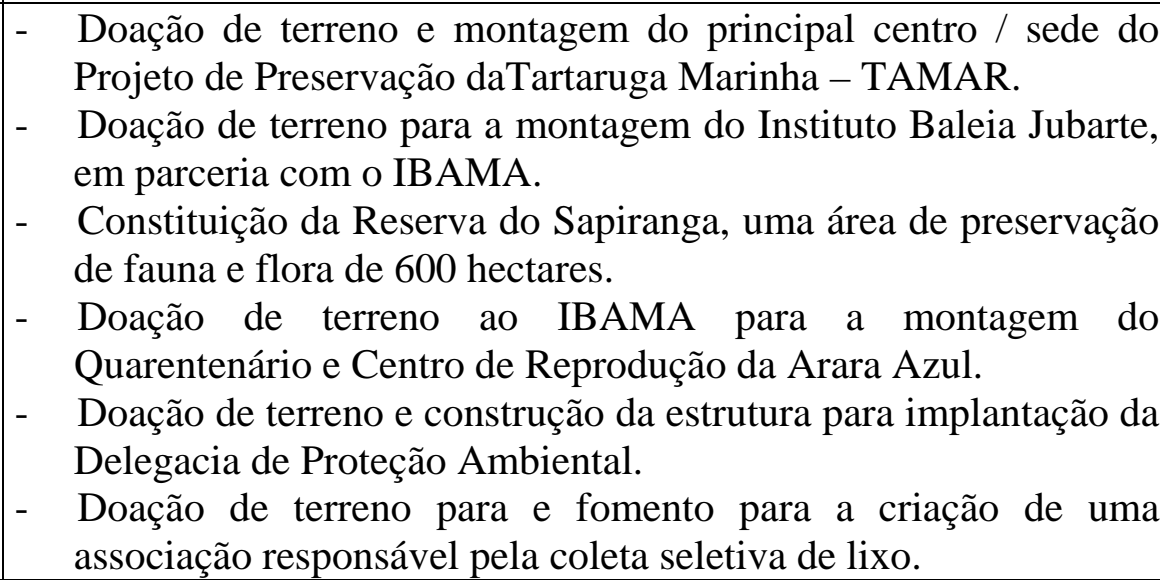 \\
\hline $\begin{array}{l}\text { Manutenção da vila de } \\
\text { pescadores e outras } \\
\text { políticas e ações sociais }\end{array}$ & 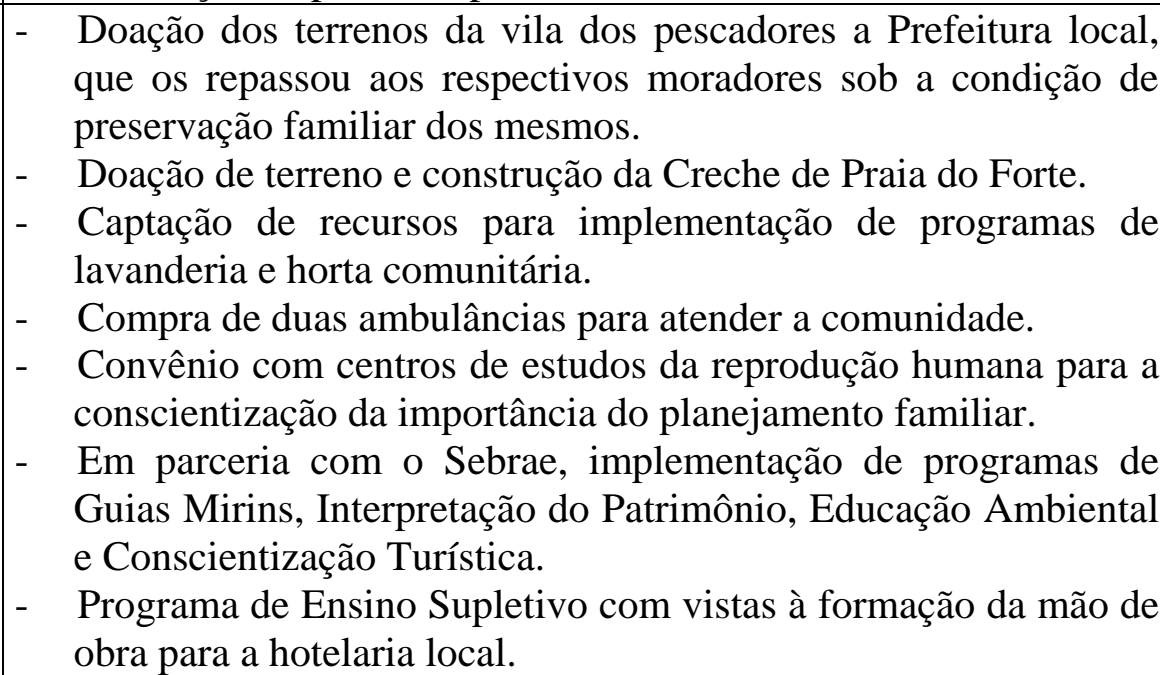 \\
\hline $\begin{array}{lr}\text { Políticas e ações } & \text { de } \\
\text { preservação } & \text { e } \\
\text { desenvolvimento } & \text { do } \\
\text { patrimônio. } & \end{array}$ & $\begin{array}{l}\text { - Articulação de patrocínio e viabilização da restauração das } \\
\text { ruínas do antigo Castelo de Garcia D’Ávila, constituindo um } \\
\text { importante ponto de visitação da área. } \\
\text { - Articulação do PRODETUR e viabilização da implantação da } \\
\text { infra-estrutura de saneamento, pavimentação e iluminação } \\
\text { pública da Vila dos Pescadores e seu entorno. }\end{array}$ \\
\hline
\end{tabular}

Fonte: Adaptado de Cardoso (2005) e Gomes (1997).

Analisando todo esse processo do ponto de vista da NEI, pode-se constatar que, com a criação da FGD, o Klaus Peters criou uma fantástica estrutura de governança para o desenvolvimento da área. Com a mesma, ele pôde não apenas manter os bens públicos naturais e culturais, 
como viabilizou o desenvolvimento dos mesmos como atrativos turísticos. O projeto TAMAR, por exemplo, que em função das tartarugas implica na proteção das praias e dos arrecifes, recebe uma visitação diária de até duas mil pessoas dia ${ }^{16}$.

Da mesma forma, um outro exemplo fantástico de manutenção e desenvolvimento dos bens públicos, é a preservação da vila dos pescadores - com os pescadores. Impedindo o boom especulativo da vila, conseguiu-se a proeza de preservar e desenvolver o grande atrativo turístico que é o povo baiano e sua cultura popular. Tudo isso, por sua vez, junto com a possibilidade de que esse povo usufrua também de uma parte dos frutos do desenvolvimento turístico empreendido.

Do ponto de vista da dinâmica econômica, vendendo os terrenos de forma gradativa e ordenada, foi possível configurar um conjunto de empresários e estabelecimentos de elevado padrão, interessados em estratégias de qualidade crescente. Reduziram-se dessa maneira os riscos de estratégias predatórias / seleção adversa. Assim, não por acaso, tornou-se possível a criação de uma ativa associação empresarial - a Turisforte, que cada vez mais atua em parceria com a FGD no sentido de desenvolver e divulgar o destino Praia do Forte.

Por todos esses processos, Praia do Forte constitui-se hoje num dos melhores complexos turísticos de sol e praia do país. Ele é sem dúvida um excelente destino e de baixíssimos custos de transação. De fato, quer se fique no EcoResort ou num hotel ou pousada mais modestos, ir para Praia do Forte é certeza de uma boa estadia. A incerteza e os riscos são mínimos. Dessa maneira, mesmo sem a participação de cadeias internacionais, ou de uma maior integração vertical com operadoras e agencias de viagem, Praia do Forte é um grande sucesso.

Como se observa, à luz da NEI o sucesso de Praia do Forte não é nenhum enigma. Ao contrário, se analisamos a estrutura de governança construída a partir da FGD, são muito claras as razões de seu sucesso. Esse sucesso, contudo, não é facilmente generalizável. Ocorre que FGD só funciona porque por trás dela está o Klaus Peters. Uma espécie de empresário esclarecido, dono inicial de toda a área, que percebeu que tinha muito mais a ganhar, como de fato ganhou, adotando uma estratégia de crescimento equilibrado num horizonte de longuíssimo prazo.

\footnotetext{
${ }^{16}$ Como as praias no Brasil não são privatizáveis, sem o projeto TAMAR seria muito difícil impedir a proliferação das costumeiras barracas (bares) de praia por toda a orla de Praia do Forte.
} 
Infelizmente, na grande maioria das praias não existem Klaus Peters. O poder público, por outro lado, está nas mãos de pequenas prefeituras, dominadas, quase sempre, por políticos pouco esclarecidos cujo horizonte de planejamento é de no máximo 4 anos. Nesse contexto, os riscos e custos de transação são naturalmente distintos e muito maiores. Assim, para viabilizar dinâmicas virtuosas, como as de Praia do Forte, em toda a costa brasileira, não basta, e muitas vezes não será possível, replicar a FGD. Outras estruturas de governança, portanto, terão de ser pensadas e desenvolvidas.

\section{Conclusões}

A partir da análise desenvolvida fica bastante claro por que o turismo no Brasil, em que pesem todas as belezas naturais e culturais, ainda não deu o tão esperado salto. Atrativos turísticos são importantes, mas, por si só, não levam a nada. Neste sentido, a idéia de que o turismo, no Brasil, é uma rota de desenvolvimento natural e fácil é completamente equivocada. O desenvolvimento turístico não é um processo simples, e muito menos natural em países subdesenvolvidos como o Brasil. Isso fica evidente: na dinâmica perversa percebida em vários dos novos complexos nordestinos; na análise teórica do setor, tomando por base a NEI; e também no estudo do caso de Praia do Forte.

Por mais paradoxal que pareça, em países subdesenvolvidos é muito mais fácil desenvolver indústrias tecnologicamente avançadas do que o turismo. Um complexo industrial pode ser construído como um enclave auto-contido em qualquer região produtora ou de fácil acesso de matérias primas. Uma vez implantado, suas próprias barreiras naturais impedem o estabelecimento de dinâmicas concorrenciais predatórias. Seus produtos, por outro lado, são via de regra bens privados e, desde que com preços competitivos, podem ser transportados para qualquer lugar do mundo sem maiores percalços e reclamações. Nada disso é verdade ou possível no turismo.

No turismo é o cliente que vem até a matéria prima, e logo ao subdesenvolvimento. A matéria prima, por sua vez, mesmo transformada em produto turístico, não é constituída de bens privados, mas de bens públicos, quase sempre naturais e de difícil coordenação. Os problemas enfrentados pelo turismo, nesse sentido, são muito mais profundos e complexos que os de qualquer setor ou complexo industrial. Não podem, portanto, ser superados por simples políticas de expansão de infra-estrutura como vem sendo tentado. 
Como visto, para que o turismo brasileiro realmente avance, é necessário criar também boas e apropriadas estruturas de governança. Estruturas que venham a regular as ações dos agentes públicos, privados e não governamentais envolvidos com toda a cadeia produtiva do setor e seus destinos. Essas estruturas, como constatado, não são de fácil desenvolvimento. Ao contrário, são arranjos institucionais bastante complexos e para os quais não existe um padrão dominante. Não existe alternativa, porém, se não apreender a desenvolvê-las e adotá-las.

\section{Referências Bibliográficas}

AKERLOF, George. 1970. The market for lemmons: quality uncertainty and the market mechanism. Quaterly Journal of Economics, n.84.

ALBAN, Marcus. 2004. Turismo no Brasil: a estratégia de expansão espacial e seus problemas, In: Encontro Nacional de Turismo de Base Local. Curitiba: Anais.

AZEVEDO, Paulo F. 1997. Nova Economia Institucional, In: P.F. Azevedo, E.M.M.Q. Farina e S.M. Saes, Competitividade, Estado, Mercado e Organizações. São Paulo: Singular.

BENI, Mário C. 1998. Análise Estrutural do Turismo. São Paulo: SENAC.

CARDOSO, Roberta C. 2005. Dimensões Sociais do Turismo Sustentável: estudo sobre a contribuição dos resorts de praia para o desenvolvimento das comunidades locais. Tese de doutorado, Programa de Administração da EAESP-FGV. São Paulo.

COASE, Ronald H. 1988. The Nature of the Firm. Econômica, n.4, 1937, reimpresso em Ronald H. COASE, The Firm, the Market and the Law. Chicago: University of Chicago Press.

EMBRATUR. Anuário Estatístico. Brasília, diversos números. 1992. Programa de Ação para o Desenvolvimento do Turismo no Nordeste. Brasília.

FERNANDES, Ivan P. e COELHO, Márcio F. 2002. Economia do Turismo. Rio de Janeiro: Campus.

GARRIDO, Inez N.D.A. 2002. Modelos Multiorganizacionais no Turismo: cadeias, clusters e redes. Salvador: Secretaria da Cultura e Turismo da Bahia.

GEE, Chuck Y. e FAYOS-SOLÁ, Eduardo (org). 2003. Turismo Internacional: uma perspectiva global. São Paulo: OMT- Bookman.

GOMES, Lirandina. 1997. Praia do Forte BA: o paraíso e suas contradições, In: Adyr A B Rodrigues (org). Turismo. Modernidade. Globalização. São Paulo: HUCITEC.

LAGE, Beatriz e MILONE, Paulo C. 1999. "Impactos Socioeconômicos Globais do Turismo”, In: Beatriz H.G. Lage e Paulo C. Milone (orgs). Turismo: teoria e prática. São Paulo: Atlas.

NORTH, Douglas. 1981. Structure and Change in Economic History. New York: W.W. Norton.

Press. 1990. Institutions, Institutional Change and Economic Performance. Cambridge University 
Liberal.

1994. Custos de Transação, Instituições e Desempenho Econômico. Rio de Janeiro: Instituto

OMT. Organização Mundial do Turismo. 2005. Tourism Market Trends. Madrid.

OSTROM, Vincent e OSTROM, Elinor. 1977. Public Goods and Public Choices. In: E.S. SAVAS (ed.). Alternatives for Delivering Public Services: Toward Improved Performance. Boulder: Westview Press.

PETROCCHI, Mario. 2001. Gestão de Pólos Turísticos. São Paulo: Futura.

PROSERPIO, Renata. 2003. O Avanço das Redes Hoteleiras Internacionais no Brasil: 1994 - 2002. Tese de doutorado, Programa de Ciências da Comunicação da ECA-USP. São Paulo.

RODRIGUES, Adyr A. B. 2001. Percalços do Planejamento Turístico: o PRODETUR Nordeste, In: Adyr A. B. Rodrigues (org). Turismo e Geografia. São Paulo: HUCITEC.

SILVA, Jorge Antônio S. 2004. Turismo, Crescimento e Desenvolvimento: uma análise urbanoregional baseada em cluster. Tese de doutorado, Programa de Ciências da Comunicação ECA-USP. São Paulo.

WILLIAMSON, Oliver. E. 1996. The Mechanisms of Governance, Oxford, Oxford University Press. 1991. Comparative Economic Organization: the analysis of discrete structure alternatives, Administrative Science Quartely, v. 36.

1985.The Economic Institutions of Capitalism: Firms, Markets, Relational Contracting. New York: The Free Press.

Press.

1975. Markets and Hierarchies: analysis and antitrust implications. Nova York: The Free

ZYLBERSZTAJN, Décio. 1995. Estruturas e Governança e Coordenação do Agribusiness: uma aplicação da Nova Economia Institucional. Tese de Livre Docência, Faculdade de Economia e Administração da USP. São Paulo.

\section{Recebido em: 24/06/2006 (1 ${ }^{\text {a }}$ versão) 19/03/2007 (2ª versão) \\ Aprovado em: 19/03/2007}

